\title{
POLÍTICAS, CURRÍCULO E PRÁTICAS DOCENTES: os impactos postos pela Covid-19 no contexto escolar
}

\author{
Flávia Marcele Cipriani \\ Antonio Flavio Barbosa Moreira \\ Cintia Chung Marques Corrêa
}

\section{Resumo}

O artigo focaliza a reflexão e análise de mudanças e permanências, mediante os impactos no contexto escolar, ocasionados pela Covid-19. As políticas educacionais, o currículo e a avaliação foram abordados no estudo, que contou com a participação de 209 professores da educação básica, na cidade de Juiz de Fora, Minas Gerais. O questionário online foi utilizado como técnica de coleta de dados. O objetivo da pesquisa foi valorizar as percepções e práticas docentes para verificar possíveis (des)continuidades no atípico ano letivo. A análise estatística descritiva e a análise de conteúdo proposta por Bardin (2011) corroboraram os resultados, que ressaltaram a importância de escutar os docentes e da análise das políticas curriculares para além das questões que envolvem os processos de produção, de seleção e de reprodução do conhecimento na educação brasileira, marcada por acentuadas desigualdades.

Palavras-chave: políticas educacionais; currículo; educação básica; docentes; Covid-19.

\section{TEACHING POLICIES, CURRÍCULUM AND PRACTICES: the impacts posed by Covid-19 in the school context}

\begin{abstract}
The article focuses on the reflection and analysis of changes and permanences, through the impacts on the school context, caused by Covid-19. Educational policies, curriculum and assessment were addressed in the study, which included the participation of 209 teachers of basic education in the city of Juiz de Fora, Minas Gerais. The online questionnaire was used as a data collection technique. The objective of the research was to value the perceptions and teaching practices to verify possible (dis) continuities in the atypical school year. The descriptive statistical analysis and the content analysis proposed by Bardin (2011) corroborated the results, which emphasized the importance of listening to teachers and the analysis of curricular policies in addition to the issues involving the processes of production, selection and reproduction of the knowledge in Brazilian education, marked by marked inequalities.
\end{abstract}

Keywords: educational policies; curriculum; basic education; teachers; covid-19.

\section{POLÍTICAS DE ENSEÑANZA, CURRÍCULO Y PRÁCTICAS: los impactos planteados por Covid-19 en el contexto escolar}

Resumen

El artículo se centra en la reflexión y el análisis de cambios y permanencias, a través de los impactos en el contexto escolar, causados por Covid-19. Las políticas educativas, el plan de estudios y la evaluación se abordaron en el estudio, que incluyó la participación de 209 maestros de educación básica, en la ciudad de Juiz de Fora, Minas Gerais. El cuestionario en línea se utilizó como técnica de recopilación de datos. El objetivo de la investigación fue valorar las percepciones y prácticas de enseñanza para verificar posibles (des)continuidades en el año escolar atípico. El análisis estadístico descriptivo y el análisis de contenido propuesto por Bardin (2011) corroboraron los resultados, que enfatizaron la importancia de escuchar a los docentes y el análisis de las políticas curriculares, además de las cuestiones relacionadas con los procesos de producción, selección y reproducción de conocimiento en educación brasileña, marcado por marcadas desigualdades.

Palabras clave: políticas educativas; curriculum; educación básica; profesores; covid-19. 


\section{POLÍTICAS CURRICULARES NA EDUCAÇÃO}

Ao abordar as políticas curriculares na educação, é importante considerar, segundo Lopes (2004, p. 111), que essas constituem o conhecimento escolar, "[...] construído simultaneamente para a escola (em ações externas à escola) e pela escola (em suas práticas institucionais cotidianas)". Ademais, é relevante mencionar que as políticas curriculares não se resumem somente aos documentos escritos, mas também arrolam as vivências e reconstruções dos processos de planejamento, na multiplicidade de espaços e por diversos sujeitos na educação (BALL, 1994; LOPES, 2004; CORRÊA, 2019). Ball (1994) argumenta que as políticas são compreendidas como um processo em constante (re)construção, ao considerar a diversidade das possiblidades de leituras de uma mesma política e o processo constante de reinterpretação.

No Brasil, o debate em torno das políticas curriculares é enfatizado ao considerar os possíveis elementos ideológicos que regulam as políticas públicas educacionais. Saviani (2008) reitera que a política educacional se refere às decisões que o poder público, representado pelo Estado, define em relação à educação. Nessa vertente, cabe ressaltar a seguinte reflexão: Qual o impacto dessas políticas na educação básica brasileira e como essas são desdobradas no currículo, sobretudo em tempos da pandemia, ocasionada pela Covid-19? Almeida e Jung (2018, p. 7), ao discutirem sobre essas políticas, mais especificamente sobre a nova Base Nacional Comum Curricular (BNCC) (BRASIL, 2017), indagam: "Elas representam a oportunidade de emancipação ou manipulam a educação para que essa se submeta, cada vez mais, à regulação da pátria panóptica?”. Segundo as autoras, o termo panóptico foi apropriado como metáfora que designa o poder da modernidade.

A Base Nacional Comum Curricular (BRASIL, 2017) normatiza as aprendizagens consideradas essenciais aos alunos da educação básica, em consonância com as Leis de Diretrizes e Bases da Educação (LDB) (BRASIL, 1996), com os preceitos do Plano Nacional de Educação (PNE) (BRASIL, 2014) e de acordo com as fundamentações constantes nas Diretrizes Curriculares Nacionais da Educação Básica (DCNE) (BRASIL, 2013). Nesse contexto, a BNCC tornou-se o documento de referência para a formulação dos currículos dos sistemas e das redes escolares, com os objetivos declarados de superar as fragmentações das políticas educacionais, fortalecer o regime de colaboração entre as esferas do governo e balizar a qualidade da educação no país, em contribuição com outras políticas e ações (BRASIL, 2017).

É importante enfatizar que a Constituição da República Federativa do Brasil (BRASIL, 1988) estabelece a necessidade de fixação dos conteúdos mínimos para o ensino fundamental, que assegurem a formação básica comum e o respeito aos valores culturais e artísticos, nacionais e regionais. A LDB também determina o estabelecimento de competências e diretrizes para a educação básica, que nortearão os currículos e seus conteúdos mínimos para uma formação de base comum, em colaboração entre os estados, o Distrito Federal e os municípios (BRASIL, 1996). Ademais, as novas DCNEs incluem a valorização das diferenças e o atendimento à pluralidade e diversidade cultural, que estimem o resgate e o respeito às várias manifestações de cada comunidade (BRASIL, 2013), e o PNE reconhece a necessidade de diretrizes pedagógicas para a educação básica e a Base Nacional Comum dos Currículos, com direitos e objetivos de aprendizagem e desenvolvimento dos alunos, nas quais sejam respeitadas as diversidades regional, estadual e local (BRASIL, 2014). Nessa abordagem, segundo dados da BNCC, desde o final do século XX, o foco no desenvolvimento de competências orienta o Brasil e outros países na construção de seus currículos e reconhece que, ao longo da história brasileira, enormes desigualdades educacionais foram naturalizadas em relação ao acesso e à permanência dos estudantes, ao considerar a raça, o sexo e as condições socioeconômicas (BRASIL, 2017). 
Mediante esse panorama, Young (2016, p. 24), ao chegar à ideia de “[...] conhecimento poderoso" como um princípio curricular, defende que o currículo deve representar o direito de todos os estudantes a um conhecimento especializado, que valorize as possibilidades para haver um avanço na aprendizagem. O autor questiona: "As políticas atuais do governo levam em consideração as condições para qualquer extensão significativa do direito ao conhecimento? Esse direito ao conhecimento é para poucos ou para todos?”. A partir desses questionamentos e da afirmação de Moreira e Candau (2007, p. 109), ao salientarem que "[...] a atividade intelectual centrase na crítica da cultura em que estamos imersos", acrescenta-se: O que é importante relevar na construção e no desenvolvimento dos currículos? Como em tempo de pandemia e de suspensão das aulas presenciais o currículo escolar vem sendo vivenciado? Ademais, Almeida e Jung (2018, p. 6) questionam: "Que tipo de conhecimento vale mais?".

\section{AFINAL, O QUE É CURRÍCULO?}

Diferentes perspectivas e interpretações podem emergir ao considerar o campo do currículo. A diversidade de concepções pode acarretar disputas que permeiam a influência dos diferentes discursos políticos, das políticas internacionais e nacionais, bem como dos interesses em modificar aspectos socioculturais de uma determinada sociedade. Nessa direção, segundo Corrêa (2019, p. 63), “[...] pensar sobre o processo de educação a partir do currículo, sob a influência de múltiplas interpretações numa sociedade interposta por contradições e diferentes anseios" merece destaque na abordagem do ciclo de políticas, proposto por Ball e Bowe (1992). O ciclo de políticas é reconhecido no Brasil como teoria da interpretação/tradução da política no contexto da prática, na qual a interpretação é considerada com o objetivo de aproximação do sentido da política e a tradução como compreensão do texto dentro dos limites da ação, em um processo permeado por várias práticas discursivas (HOSTINS, ROCHADEL, 2019).

O currículo, segundo Moreira e Candau (2007), constitui-se como experiências escolares em meio às relações sociais em torno do conhecimento. Essas experiências, a partir de um conjunto de esforços pedagógicos, contribuem para a construção das identidades dos estudantes. Nessa abordagem, o currículo associa-se às distintas concepções na história da educação e às influências teóricas no contexto da sociedade. Os autores afirmam que os fatores socioeconômicos, políticos e culturais contribuem para que o currículo venha a ser entendido como:

a) os conteúdos a serem ensinados e aprendidos; b) as experiências escolares de aprendizagem a serem vividas pelos alunos; c) os planos pedagógicos elaborados por professores, escolas e sistemas educacionais; d) os objetivos a serem alcançados por meio do processo de ensino; e) os processos de avaliação que terminam por influir nos conteúdos e nos procedimentos selecionados nos diferentes graus de escolarização (MOREIRA, CANDAU, 2007, p. 86).

Young (2016, p. 33) assinala que “[...] em qualquer discussão sobre o currículo, a distinção mais básica é entre o conhecimento escolar, ou curricular, e o conhecimento do dia a dia, ou da experiência que os alunos trazem para a escola". O autor ressalta, ainda, que o currículo se configura como um recurso que guia os objetivos do professor, da escola e do país, ao estimar o que é valorizado como conhecimento essencial ao acesso para todos os estudantes, que, ao compreenderem o conceito, utilizam esse em qualquer novo contexto. Moreira e Silva (2008) enfatizam que, embora questões referentes ao "como" do currículo sejam relevantes, essas somente denotam sentido em uma perspectiva que as considere mediante questões pelo "por quê" das formas de organização do conhecimento escolar. Segundo os autores, o currículo "[...] transmite visões sociais e particulares interessadas", implicadas em relação de poder, por "[...] produzir 
identidades individuais e sociais particulares" em uma "[...] história vinculada a formas específicas e contingentes de organização da sociedade e da educação" (MOREIRA, SILVA, 2008, p. 13).

Conceder maior espaço para que sejam produzidos novos sentidos para as políticas curriculares, que valorizem o currículo como espaço da pluralidade de saberes, de valores e de racionalidades que empreendam novas interpretações sobre as questões de nosso tempo, faz-se necessário (LOPES, 2004). Nesse sentido, considerando o contexto pandêmico vivenciado pela educação no país e no mundo globalizado, quais definições políticas foram legitimadas em meio à calamidade? A suspensão das aulas presenciais tem contribuído para preservar e reforçar as relações de poder, que oprimem determinados grupos e indivíduos e privilegiam outros? Como o contexto escolar se organizou e se organizará após a pandemia e quais serão os possíveis impactos no campo do currículo na educação brasileira? Afinal, o currículo, estimado como um conjunto de experiências de conhecimento que a escola oferece aos estudantes (MOREIRA, 2001), é digno de ser focado para compreender a atuação das escolas, dos docentes e as relações estabelecidas na prática curricular durante e depois do cenário atípico instaurado.

\section{A PANDEMIA COVID-19 E O CONTEXTO EDUCACIONAL}

Desde a declaração da Organização Mundial da Saúde (OMS), em março de 2020, a respeito da situação de emergência de Saúde Pública desencadeada pelo surto da doença provocada pelo novo coronavírus (SARS-CoV-2), que rapidamente se disseminou por vários países no mundo, inclusive no Brasil, vários setores da sociedade foram afetados, entre esses o sistema de educação escolar. Com a suspensão das aulas presenciais, devido às medidas adotadas para evitar a propagação do contágio do vírus, que apresenta um espectro clínico, variando de infecções assintomáticas a quadros graves que podem culminar em óbitos, as escolas têm vivenciado desafios no desenvolvimento do currículo na práxis educacional.

Nesse sentido, destaca-se o Parecer do Conselho Nacional de Educação CNE/CP n. 11/2020 (BRASIL, 2020b), organizado em colaboração com o Ministério da Educação (MEC), no qual são articuladas orientações para a realização de atividades presenciais e não presenciais, no processo de reorganização dos calendários escolares e do replanejamento curricular, em complementação ao Parecer CNE/CP n. 5/2020 (BRASIL, 2020a), ao tratar do contexto educação na pandemia. Os documentos recomendam que as soluções encontradas no âmbito das autonomias dos estados e municípios considerem o desenvolvimento das competências e habilidades propostas pela BNCC no replanejamento curricular 2020-2021.

O conjunto de recomendações menciona como objetivo a preservação da vida, a diminuição das desigualdades e o desenvolvimento de uma sociedade brasileira plural, mas assentada sobre os princípios e valores de promoção da cidadania. Por outro lado, reconhece que os maiores desafios são a grande desigualdade no acesso à internet pelos estudantes, as dificuldades dos professores em desenvolver atividades remotas, as desigualdades no índice socioeconômico e na infraestrutura das escolas. O documento afirma que, em geral, as escolas das redes públicas não conseguem fazer o monitoramento da aprendizagem das atividades não presenciais (BRASIL, 2020b). Importante destacar que o Parecer declara que as redes de escolas particulares conseguiram fazer adaptações significativas em suas unidades e que já apresentam propostas de planejamento de volta às aulas, bem como do replanejamento curricular, o que corrobora as discrepâncias do cenário vivenciado pelas redes de ensino privadas e públicas no Brasil, marcadas pelas desigualdades de condições de acesso e permanência dos estudantes.

O Parecer CNE/CP n. 11/2020 dispõe diretrizes para reabertura das escolas, de acordo com experiências internacionais. Cabe grifar que todos os países citados no documento são considerados como nações classificadas, economicamente, de primeiro mundo, o que chama a 
atenção para a internacionalização de práticas não contextualizadas com a realidade brasileira. Nesse sentido, ao considerar o currículo, MOREIRA (2012) afirma que, na medida em que é sugerido o que deva ser, inevitavelmente há relações de poder envolvidas, significando que, ao selecionar, destacar, ocultar, propor e impor, exemplos da ação do poder nos intercâmbios do processo de internacionalização são constituídos. Ademais, entre as recomendações do Conselho Nacional de Educação, salienta-se a flexibilização curricular no que concerne à seleção de objetivos ou marcos de aprendizagens essenciais e a afirmação de que a principal finalidade do processo educativo é o atendimento dos direitos e objetivos de aprendizagem previstos para cada etapa educacional expressos pela BNCC (BRASIL, 2020b). Nessa vertente, enseja-se a BNCC à luz da regulação ou da emancipação? (ALMEIDA, JUNG, 2018).

No que tange à avaliação, o documento publicado pelo Conselho Nacional de Educação considera importante a avaliação diagnóstica e formativa dos alunos no retorno às aulas presenciais para avaliar as lacunas de aprendizagem, considerando o currículo efetivamente cumprido e as diferentes situações enfrentadas em cada sistema de ensino, assegurando as mesmas oportunidades a todos que participam das avaliações em âmbitos municipal, estadual e nacional (BRASIL, 2020b). No entanto, é cabível considerar a igualdade de oportunidades na educação durante e póspandemia em um sistema excludente por natureza? Qual é o efetivo papel da avaliação?

Almeida e Jung (2018, p. 5) argumentam que a educação deve representar a práxis reflexiva que possibilite a socialização do conhecimento e da participação democrática, que envolva alunos, professores e comunidade, para significação de uma escola para além da gestão neoliberal, para uma escola que se volte para a vida, para a realidade histórica deste tempo que se chama hoje. Nessa premissa, o presente estudo considerou importante, em seu percurso metodológico, saber o que os professores têm percebido em sua profissão, nas práticas ou na falta delas no contexto pandêmico, especificamente no que se refere ao desenvolvimento do currículo e ao processo avaliativo da aprendizagem dos alunos.

\section{ASPECTOS METODOLÓGICOS}

A presente pesquisa adotou a análise estatística descritiva e a técnica da Análise de Conteúdo proposta por Bardin (2011), dos dados emergentes dos 209 participantes. O caráter do estudo foi exploratório, visto que procurou entender melhor o problema ao explicitá-lo. A amostra foi selecionada por questões de conveniência e acessibilidade, ao enviar por Whats App ou Messenger o link do formulário, com questões em formato aberto e fechado, para professores atuantes na educação básica da cidade de Juiz de Fora, Minas Gerais (MG).

Segundo Bardin (2011, p. 47), a análise de conteúdo designa "[...] um conjunto de técnicas de análise das comunicações que visam obter indicadores (quantitativos ou não) que permitam a inferência de conhecimentos relativos às condições de produção/recepção (variáveis inferidas) dessas mensagens". Campos (2004, p. 613) acrescenta que a produção de inferência embasa determinadas mensagens com "[...] pressupostos teóricos de diversas concepções de mundo e com as situações concretas de seus produtores ou receptores", de acordo com o contexto histórico e social em que estão inseridos.

Ressalta-se que, na utilização da técnica de análise de conteúdo, foram consideradas as seguintes fases: pré-análise, que consistiu na organização e leitura flutuante em um primeiro contato com os dados submetidos ao corpus da análise; exploração do material, na qual foram escolhidas as unidades de codificação, que incluíram palavras, sentenças, frases ou parágrafos, para fazer a escolha das unidades de registro, das quais emergiram as categorias por classificação e agregação, a partir do agrupamento de elementos com características comuns; tratamento dos resultados, fase em 
que se fez a inferência e interpretação para que os resultados fossem significativos e válidos (BARDIN, 2011; CÂMARA, 2013).

Cabe destacar que todos os participantes leram o Termo de Consentimento Livre e Esclarecido (TCLE), inicialmente apresentado no instrumento de pesquisa, e marcaram a opção de aceite, antes de responderem ao questionário on-line. Ressalta-se, ainda, que foram estimadas, neste artigo, duas questões de formato fechado referentes ao perfil dos participantes e duas questões em formato aberto, a saber: Considerando o desenvolvimento do currículo, em sua opinião, qual tem sido a interferência (se houve) da pandemia? Como você tem conduzido o processo de avaliação da aprendizagem dos alunos neste período de quarentena?

\section{DISCUSSÃO DOS RESULTADOS}

A pesquisa contou com a participação de 209 professores atuantes na educação básica, no município de Juiz de Fora, MG. A Figura 1, a seguir, representa a distribuição dos docentes, de acordo com as etapas educacionais em que lecionam:

Figura 1: Atuação nas etapas educacionais

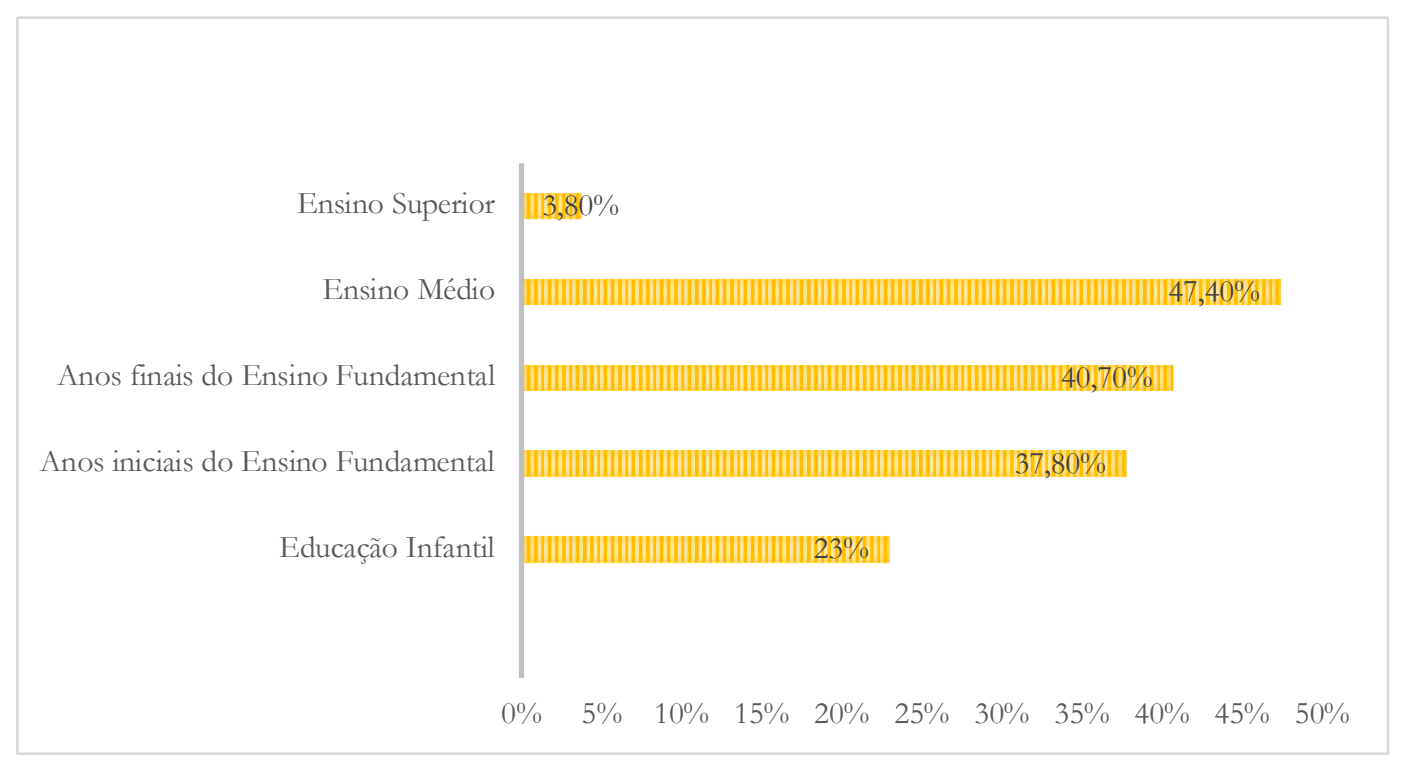

Fonte: Autores, 2020.

Os dados revelaram que a maior concentração de participantes leciona no ensino médio (47,4\%). Em seguida, respectivamente, nos anos finais do ensino fundamental (40,7\%), nos anos iniciais do ensino fundamental (37,8\%), na educação infantil $(23 \%)$ e no ensino superior $(3,8 \%)$. Cabe esclarecer que alguns professores atuantes na educação básica mencionaram atuar também no ensino superior e, por esse motivo, apesar de o foco desta pesquisa não ser nessa etapa educacional, um pequeno índice apareceu nos resultados.

Em relação às redes nas quais os participantes lecionam, foi constatado que a grande maioria atua somente na rede de ensino privada (65,55\%). Alguns exercem a docência nas redes privadas e públicas, em esfera municipal (11,96\%), estadual (9,09\%), municipal e estadual $(1,44 \%)$. Acrescenta-se que há profissionais que lecionam, exclusivamente, em escolas da rede pública municipal (4,31\%), estadual (1,91\%), municipal e estadual (3,83\%) e federal (1,91\%). A Figura 2 representa esses dados: 
Figura 2: Redes de ensino

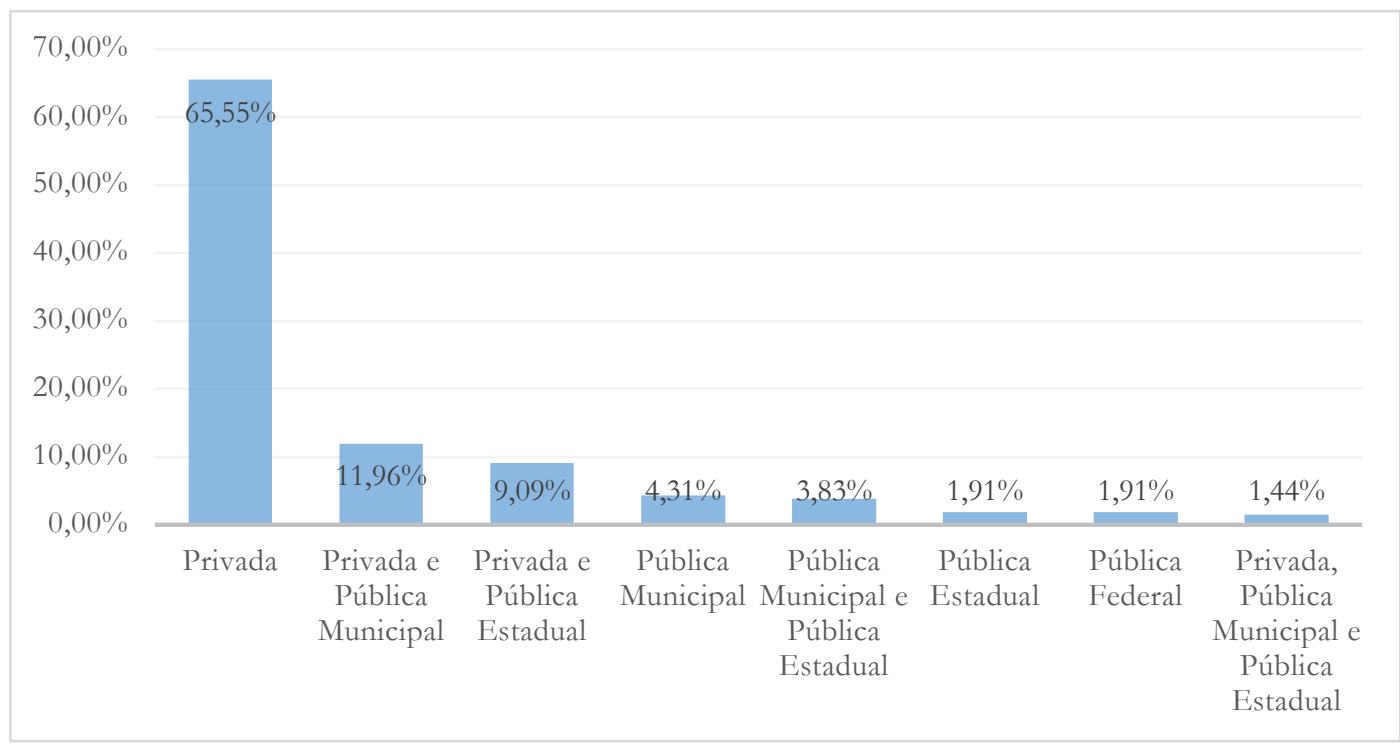

Fonte: Autores, 2020.

Os temas emergidos da análise foram agrupados de acordo com as respostas dos participantes ao questionário. Em todo o processo, procurou-se preservar, na íntegra, os sintagmas escritos pelos professores. Sublinha-se que, devido ao elevado número de participantes e às consequentes respostas discursivas, foram dispostos nas tabelas apenas exemplos de pronunciamentos que levaram à saturação dos resultados. Os participantes não foram identificados devido à garantia de anonimato. Vale lembrar que os depoimentos estão integrados em um único trecho e separados por ponto e vírgula.

A Tabela 1 retrata a categoria Desenvolvimento do currículo. Destaca-se que foram obtidas respostas direcionadas a indicadores que inferiram as seguintes unidades: "Redução de conteúdos e tempos", "Flexibilização e adaptação", "Clareza do que é essencial", "Mudança na forma de ensinar e aprender", "Prejuízos pelo distanciamento físico" e "Não houve interferências".

Tabela 1: Quadro categorial I

\begin{tabular}{|l|l|}
\hline \multicolumn{1}{|c|}{ Categoria: Desenvolvimento do Currículo } \\
\hline Temas & \multicolumn{1}{|c|}{ Exemplos de respostas dos participantes } \\
\hline \multirow{3}{*}{$\begin{array}{l}\text { Redução de conteúdos e } \\
\text { tempos }\end{array}$} & $\begin{array}{l}\text { As horas reduzidas de aula, com certeza, comprometerão o } \\
\text { cumprimento do currículo; está havendo um atraso significativo, pois o } \\
\text { número de aulas diminuiu e o rendimento é muito menor; há um grande } \\
\text { atraso naquilo que precisávamos caminhar com os alunos, estamos } \\
\text { tentando ajustar; teremos que adequar o currículo ao tempo e dar } \\
\text { preferência aos pré-requisitos do conteúdo; a pandemia está } \\
\text { prejudicando a organização do currículo no sentido de cumprimento de } \\
\text { conteúdos; a quantidade de aulas online é menor do que as presenciais, } \\
\text { então, a sequência ideal de planejamento foi alterada; os conteúdos } \\
\text { curriculares estão sendo trabalhados de forma mais lenta; atraso na } \\
\text { matéria, pois diminuímos as horas de aula. }\end{array}$ \\
\hline \multirow{3}{*}{ Flexibilização e adaptação } & $\begin{array}{l}\text { Tivemos que adaptar tudo, desde planejamento, atividades, avaliações, } \\
\text { calendário escolar etc.; é preciso adaptar o currículo à nova realidade; } \\
\text { acredito que a pandemia nos forçou a flexibilizar a ideia de uma }\end{array}$ \\
\hline
\end{tabular}




\begin{tabular}{|c|c|}
\hline & $\begin{array}{l}\text { educação tradicional conteudista e com o objetivo único de cumprir } \\
\text { programas; vi a necessidade de adaptações na ordem dos objetos de } \\
\text { conhecimentos a serem explorados, visando favorecer o modelo de aula } \\
\text { que estamos tendo que ministrar; tenho flexibilizado o volume para } \\
\text { conseguir ter um melhor aproveitamento; tem que ser flexibilizado, não } \\
\text { temos condições de aprendizagem integral sem aulas presenciais; } \\
\text { estamos adaptando os conteúdos e fazendo algo com o que podemos e } \\
\text { conseguimos; o conteúdo deve ser flexível e não tão rígido; as escolas } \\
\text { tiveram que se adaptar a esta nova forma de ensino/aprendizagem, para } \\
\text { continuar ofertando aos seus alunos continuidade dos conteúdos } \\
\text { curriculares. }\end{array}$ \\
\hline Clareza do que é essencial & $\begin{array}{l}\text { Neste momento, o mais importante é priorizarmos a qualidade do } \\
\text { nosso trabalho, em detrimento da quantidade de conteúdo; a pandemia } \\
\text { está fazendo com que seja revisto o currículo, a intensidade e prioridade } \\
\text { de conteúdos; adaptação ao currículo essencial para o aluno; a } \\
\text { interferência é dar prioridade ao que compõe o eixo duro; procurei } \\
\text { focar mais nas habilidades essenciais, no que não pode ficar de lado; o } \\
\text { currículo teve que passar por revisão para contemplar as necessidades } \\
\text { desse momento; acredito que tem sido útil para avaliarmos a quantidade } \\
\text { enorme de conteúdos passados aos alunos e pouco assimilados pelos } \\
\text { mesmos; o material da rede estadual privilegia os conhecimentos que } \\
\text { consideram mais essenciais. }\end{array}$ \\
\hline $\begin{array}{l}\text { Mudança na forma de } \\
\text { ensinar e aprender }\end{array}$ & $\begin{array}{l}\text { A forma como a construção da aprendizagem vem se dando mudou } \\
\text { completamente; foi preciso reorganizar e modificar o modelo } \\
\text { educacional, do sentido presencial para o não presencial; o professor } \\
\text { tem que mudar sua aula, fazendo o aluno se conectar com novos } \\
\text { raciocínios, e isso é muito difícil para aqueles que necessitam do livro } \\
\text { didático como forma de ensinar/aprender; acelerou o processo de } \\
\text { informatização para os docentes; mudou-se o processo, mas estamos } \\
\text { nos readaptando e dando continuidade às atividades; a dinâmica de } \\
\text { organização de todo o processo educacional está sendo outra; } \\
\text { precisamos nos adequar ao momento e a uma nova forma de ministrar } \\
\text { os conteúdos. }\end{array}$ \\
\hline $\begin{array}{l}\text { Prejuízos pelo } \\
\text { distanciamento físico }\end{array}$ & $\begin{array}{l}\text { Um dos grandes desafios neste momento, em relação ao currículo, é } \\
\text { desenvolver a interação e a socialização, pois, com o isolamento social, } \\
\text { isso não está acontecendo; a distância para a educação infantil é um } \\
\text { elemento prejudicial para o desenvolvimento de um trabalho com os } \\
\text { pequenos; a perda que percebo é a falta do contato social, tão necessário } \\
\text { à educação; o distanciamento físico tirou um dos principais e talvez } \\
\text { mais importante meio de desenvolvimento da educação infantil: o } \\
\text { convívio social; sinto muito a falta do contato físico, esse tem sido o } \\
\text { principal desafio; com certeza, a parte da socialização será a mais afetada } \\
\text { em relação ao conteúdo; ministrar conteúdos novos para alunos apenas } \\
\text { virtualmente é complicado, há uma perda, o que afeta, diretamente, no } \\
\text { cumprimento do currículo; a interação (ou ausência dela) tem afetado } \\
\text { muito o processo de ensino-aprendizagem. }\end{array}$ \\
\hline Não houve interferências & $\begin{array}{l}\text { Por enquanto, estamos seguindo o currículo normalmente, a escola } \\
\text { manteve o calendário, os alunos não ficaram sem aulas; não houve } \\
\text { interferência no currículo; por enquanto, não houve alteração; estamos } \\
\text { tentando não mudar o planejamento em função das avaliações externas; } \\
\text { não observei nada que tivesse sido obstáculo no cumprimento do } \\
\text { programa; não houve interferência no que tange à minha disciplina; }\end{array}$ \\
\hline
\end{tabular}




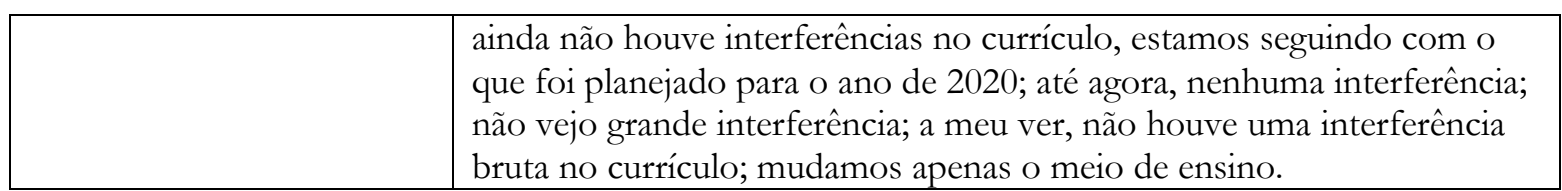

Fonte: Autores (2020)

Os professores expressaram preocupação com a diminuição da carga horária das disciplinas e dos conteúdos. $\mathrm{O}$ atraso no ritmo das aulas e no tempo de aprendizagem dos alunos foram recorrentemente mencionados como fatores prejudiciais ao desenvolvimento do currículo durante a pandemia. A palavra "conteúdos" foi repetida com frequência nos temas, o que corrobora a ideia de relação do currículo apenas ao conhecimento, ao conteúdo a ser ensinado constante nos planos pedagógicos. Macedo (2012) afirma que a centralidade no conhecimento tende a reduzir a educação ao ensino. Tal fato desconsidera as múltiplas facetas da aprendizagem. Moreira e Silva (2008, p. 134) ressaltam que "[...] muitos professores querem ajudar seus alunos a identificar, compreender e produzir conhecimentos úteis. Mas o que constitui conhecimento útil?”. Os autores questionam, ainda, o seguinte: "Como lidar com essa diversidade e essas diferenças sociais em termos intelectuais, emocionais e práticos?". Essas parecem ser questões importantes e atuais ao currículo, no contexto da educação durante e após a calamidade instaurada pela Covid-19.

A necessidade de flexibilização e de adaptação curricular foram relatadas pelos participantes ao utilizarem os verbos contextualizar, flexibilizar, (re)adaptar e (re)adequar o currículo. Também, a clareza do que, realmente, é essencial, necessário, importante ou prioridade foi frequentemente destacada pelos professores, que afirmaram a emergência de mudanças e reestruturação do currículo nas escolas. Macedo (2012, p. 734-735) pondera ser fundamental "[...] redefinir os sentidos de currículo para além do conhecimento" e defende a aposta no currículo como "[...] instituinte de sentidos, como enunciação da cultura, como espaço indissociável em que os sujeitos se tornem sujeitos por meio de atos de criação". Nessa perspectiva, valorizam-se os processos que implicam o diálogo com os saberes disciplinares e com outros saberes socialmente produzidos (MOREIRA, CANDAU, 2007).

A reflexão sobre as práticas docentes, sobre novas formas de ensinar e aprender, segundo os participantes, acelerou o processo de informatização e acentuou a relevância de maior suporte e de uma contínua formação que viabilize condições para melhor atuação dos profissionais na educação. Almeida e Jung (2018) reiteram a valorização atual do professor polivalente, que atue em equipe e que tenha disponibilidade para trabalhar conectado em uma rede de comunicação, inclusive virtual. Afirmam os autores que, nessa direção, cabe ao sistema educacional dar o suporte necessário e as condições adequadas aos profissionais da educação, a fim de prepará-los para lidar com o imprevisível, adaptar-se às novas situações e inovar.

Os professores salientaram que os prejuízos causados pelo distanciamento social trouxeram à tona grandes desafios à interação e socialização e que as relações de forma virtual não são equivalentes àquelas em que há o contato físico. A situação mostra que, na educação básica, as mediações e a aprendizagem de forma remota precisam ser reconsideradas e, cuidadosamente, analisadas. Por fim, na categoria "Desenvolvimento do currículo", um grupo de participantes considera que não ocorreram impactos no currículo com a pandemia e as medidas tomadas durante o distanciamento social.

Um fator importante que merece ser mencionado é que, na análise, 38 professores não responderam a essa questão ou revelaram que ainda não estavam lecionando remotamente na época em que responderam ao questionário, no período entre os meses de abril e maio do ano letivo de 2020. Segundo Bernstein (1998), enquanto algumas vozes são ouvidas, outras são silenciadas, 
porém, os sentidos são produtos tanto do que se ouve quanto do que é silenciado. Nesse processo, constituem-se as identidades e a diferença entre elas.

A Tabela 2 representa o quadro da categoria relacionada à avaliação do processo de aprendizagem dos alunos. Os participantes anunciaram que os aspectos qualitativos e quantitativos da avaliação foram estimados durante a pandemia. Ressalta-se que um grupo de participantes relatou apenas aspectos quantitativos e outro grupo, somente aspectos qualitativos. Constatou-se que ambos os aspectos foram considerados por um grupo e, ainda, que emergiram relatos de profissionais que afirmaram a não condução o processo de avaliação dos estudantes durante a suspensão das aulas presenciais.

Tabela 2: Quadro categorial “Avaliação”

\begin{tabular}{|c|c|}
\hline \multicolumn{2}{|c|}{ Categoria: Avaliação do processo de aprendizagem } \\
\hline Temas & Exemplos de respostas dos participantes \\
\hline $\begin{array}{l}\text { Aspectos qualitativos e } \\
\text { quantitativos }\end{array}$ & $\begin{array}{l}\text { Avaliações informais e avaliação formal no Forms. Testes e provas online, } \\
\text { trabalhos diversificados enviados por e-mail; pela participação e testes } \\
\text { rápidos pelo Forms; várias atividades diversificadas, além do simulado } \\
\text { proposto pela instituição; estamos avaliando através de participação, } \\
\text { atividades avaliativas e provas online. Participação em aula, trabalho, } \\
\text { atividades e prova através do Google Forms; com formulários, produção } \\
\text { de vídeos, jamboards etc.; valorizando as atividades desenvolvidas, bem } \\
\text { como avaliações sobre o conteúdo de maneira mais objetiva; tentamos } \\
\text { avaliar todo o percurso, mas a instituição exigiu uma "atividade } \\
\text { avaliativa" formal feita no Google Forms; feedback espontâneo durante as } \\
\text { aulas e avaliações simuladas na plataforma; debates sobre os assuntos de } \\
\text { aulas anteriores e Forms. }\end{array}$ \\
\hline Aspectos quantitativos & $\begin{array}{l}\text { As avaliações são digitais através da plataforma; avaliações objetivas } \\
\text { postadas nas plataformas. Simulados online, montados por mim e } \\
\text { aplicados pela plataforma da escola; simulados online; tenho utilizado } \\
\text { bastante o formulário do Google; os alunos têm feito as avaliações no } \\
\text { Forms; através do Google Forms, montamos a avaliação e os alunos têm } \\
\text { um prazo de } 15 \text { dias para responder; através de uma verificação de } \\
\text { aprendizagem aplicada pela plataforma Forms; por verificação de } \\
\text { aprendizagem, agendada e orientada em plataforma digital; provas; } \\
\text { problemático, uma vez que, quando avaliados, é apenas por questões } \\
\text { objetivas. }\end{array}$ \\
\hline Aspectos qualitativos & $\begin{array}{l}\text { O processo tem se dado a partir da participação dos alunos por áudio e } \\
\text { pelo Chat das plataformas em uma avaliação contínua; avaliação diária, } \\
\text { através das participações dos alunos e trabalhos; através de trabalhos } \\
\text { práticos com atividades realizadas e filmadas por eles em casa. Através } \\
\text { da participação, da elaboração de perguntas e realização de atividades } \\
\text { propostas; perguntas e questionamentos durante as aulas; perguntas } \\
\text { pelo Chat e trabalhos; através de troca de ideias, jogos e atividades; } \\
\text { participação do aluno durante as aulas online, bem como realização das } \\
\text { atividades enviadas; diálogos com os pais; através de fóruns e Chats; } \\
\text { atividades diversificadas e processuais; ao final de cada dia, temos um } \\
\text { feedback de cada responsável, por meio de mensagem, vídeo ou foto; } \\
\text { avaliação contínua, de participação e envolvimento; temos uma } \\
\text { avaliação processual; participação nos encontros online e devolução das } \\
\text { atividades propostas; avaliação contínua e de forma coletiva; pelos } \\
\text { diversos tipos de registros realizados pelas crianças com auxílio dos } \\
\text { familiares; a participação dos estudantes tem sido um meio de avaliação, }\end{array}$ \\
\hline
\end{tabular}




\begin{tabular}{|l|l|}
\hline & $\begin{array}{l}\text { o retorno que recebo através de fóruns e questionamentos; } \\
\text { acompanhamento diário das atividades propostas. discussões orais e } \\
\text { escritas; jogos; atividades em formulários online etc. }\end{array}$ \\
\hline & $\begin{array}{l}\text { Não tenho avaliado; não é possível avaliar à distância no caso da } \\
\text { educação infantil; a avaliação acontecerá somente quando a volta às } \\
\text { aulas acontecer. Não posso relatar; até o presente momento, não } \\
\text { estamos avaliando os alunos. Não tenho realizado avaliação da } \\
\text { aprendizagem; não estou conseguindo realizar a avaliação. Não tenho } \\
\text { feito avaliação formal; não há avaliações de nota ou de participação } \\
\text { nesse período; ainda não realizamos avaliações, mas os exercícios } \\
\text { enviados pelos alunos poderão ser usados como avaliações; com a } \\
\text { suspensão do calendário, as avaliações também foram suspensas; não } \\
\text { houve processo de avaliação ainda. Não estamos avaliando por } \\
\text { enquanto; durante o período de aulas online, não haverá avaliações. }\end{array}$ \\
\hline
\end{tabular}

Fonte: Autores, 2020.

Consideráveis dificuldades, ao conduzirem o processo de avaliação da aprendizagem dos alunos de forma remota foram expressas pelos professores. Notaram-se os esforços e a preocupação dos docentes ao considerarem não apenas os conteúdos. Por meio de diversos trabalhos, das atividades, do envolvimento das famílias e, principalmente, da participação dos alunos, o processo avaliativo foi reconhecido pelos participantes. Mas, será mesmo que todos os alunos conseguem se expressar de forma efetiva via online para que sejam avaliados? É possível valorizar a avaliação formativa, virtualmente, na educação básica? Os alunos têm suporte, maturidade e formação consolidada para essa prática? Garcia, Esteban e Serpa (2015, p. 141), ao abordarem a questão "Quem estamos formando da forma que avaliamos?", afirmam que essa pergunta concede abertura para diversas reflexões e estimula o debate sobre possibilidades de compreensão mais profunda das práticas escolares, as realizadas e as propostas. Segundo a autora, “[...] como o cotidiano permite múltiplas experiências e a avaliação as atravessa, indagar seus efeitos é indispensável para a compreensão da escolarização como fenômeno social complexo".

Cabe realçar que a condução do processo avaliativo, restritamente por meio de aspectos quantitativos, foi explícita por um grupo de professores como prática determinada pelas instituições educacionais. Formulários on-line com questões objetivas foram relatados como frequentes meios de avaliação nesse período de aulas não presenciais, reforçando que os aspectos quantitativos ainda tendem a preponderar os qualitativos. Outros apontamentos que merecem destaque se voltaram para a afirmação de que os professores não podem ainda relatar como o processo avaliativo será conduzido ou que, durante o período de aulas não presenciais, não haverá avaliação. De acordo com Garcia, Esteban e Serpa (2015), avaliação e currículo estão articulados e marcados pelo intenso confronto cultural no cotidiano escolar e que, apesar de muitas e constantes críticas, o conhecimento se mantém vigoroso nas relações escolares e na formulação de políticas públicas para a educação, que consideram a avaliação como regulação, controle e uniformização.

Nesse panorama, entre o conjunto de recomendações publicadas pelo Conselho Nacional de Educação (BRASIL, 2020b), salienta-se a avaliação dos alunos no retorno às aulas presenciais para que seja avaliado o que foi aprendido e quais são as lacunas de aprendizagem. Questões abertas, além dos testes de múltipla escolha, que avaliam quais competências e habilidades foram desenvolvidas pelos alunos durante o período de isolamento, foram especificados no documento. Retoma-se, por conseguinte, a questão: "Quem estamos formando da forma que avaliamos?" (GARCIA, ESTEBAN, SERPA, 2015). 
Para concluir este artigo, reitera-se que o contexto pandêmico emergido pela Covid-19 ressalta a importância dos valores, das normas e dos símbolos relacionados às políticas públicas educacionais brasileiras terem suas interpretações e traduções consideradas no cotidiano da educação escolar. $\mathrm{Na}$ análise da política como interpretação e tradução, as histórias e ideologias dos receptores e os textos da política merecem atenção no processo de reinterpretação e no caminho em que é feito (BALL, BOWE, 1992).

O cenário atípico instaurado na sociedade impactou o sistema de educação escolar, que, de maneira abrupta, teve suas aulas suspensas. Nesse sentido, novos desafios no desenvolvimento do currículo foram acentuados, principalmente ao se considerar as condições de acesso dos estudantes, as discrepâncias entre as redes de ensino mediante a possibilidade das aulas remotas e os conhecimentos essenciais a serem valorizados.

Nesse sentido, as políticas curriculares e o currículo em si, enquanto projeto educativo, deve corroborar as discussões das "[...] interseções e as contradições entre o texto escrito e a realidade da prática cotidiana” (CORRÊAA, 2019, p. 74). A avaliação, por sua vez, como processo que se integra ao currículo, atualmente centrada no modelo de competências proposto pela BNCC, necessita, em sua regulação, denotar outros sentidos e significados aos conhecimentos considerados essenciais e à formação pela emancipação humana, sintonizada com um projeto político-social que vise à redução das diferentes formas de exclusão na sociedade. Lopes (2004) salienta que, entre essas concepções a serem desconstruídas ou construídas em novas bases, a relação entre as definições políticas e a prática, os processos de avaliação e o currículo merecem destaque.

Por fim, importa ressaltar a necessidade de ouvir e reconhecer os professores em suas práticas para que os currículos e as propostas pedagógicas sejam mais efetivos, democráticos, relevantes aos alunos e em consonância com as necessidades e realidades da educação contemporânea na sociedade. Profissionais bem preparados, que recebam condições e remunerações adequadas de trabalho e de formação continuada, podem corroborar, ainda mais, com as mudanças e transformações importantes, face aos dilemas enfrentados pela educação escolar no Brasil.

\section{REFERÊNCIAS}

ALMEIDA, Maria de Lourdes Pinto; JUNG, Hildegard Susana. Políticas curriculares e a base nacional comum curricular: emancipação ou regulação? Educação - Revista do Centro de Educação da Universidade Federal de Santa Maria, UFSM, 2018. Disponível em https://periodicos.ufsm.br/reveeducação. Acesso em 10 jul. 2020.

BALL, Stephen J. Educational reform - a critical and post-structural approach. Buckingham: Open University Press, 1994.

BALL, Stephen J.; BOWE, Richard; GOLD, Anne. Changing Schools - case studies in policy sociology. London: Routledge, 1992.

BARDIN, Laurence. Análise de conteúdo. São Paulo: Edições 70, 2011.

BERNSTEIN, Basil. Pedagogía, control simbólico e identidad. Madrid: Morata, 1998.

BRASIL. Constituição da República Federativa do Brasil (1988). Brasília, DF: Senado Federal, 1988. Disponível em http://www.planalto.gov.br/ccivil 03/constituicao/constituicao.htm. Acesso em 16 jul. 2020. 
BRASIL. Lei n. 9.394, de 20 de dezembro de 1996. Estabelece as Diretrizes e Bases da Educação Nacional. Diário Oficial da União, Brasília, 23 de dezembro de 1996. Disponível em http://www.planalto.gov.br/ccivil_03/leis/19394.htm. Acesso em 16 jul. 2020.

BRASIL. Ministério da Educação; Secretaria de Educação Básica; Secretaria de Educação Continuada, Alfabetização, Diversidade e Inclusão; Secretaria de Educação Profissional e Tecnológica. Conselho Nacional de Educação; Câmara de Educação Básica. Diretrizeses Curriculares Nacionais da Educação Básica. Brasília: MEC; SEB; DICEI, 2013. Disponível em http://portal.mec.gov.br/docman/julho-2013-pdf/13677-diretrizes-educacao-basica-2013pdf/file. Acesso em 16 jul. 2020.

BRASIL. Lei n. 13.005, de 25 de junho de 2014. Aprova o Plano Nacional de Educação - PNE e dá outras providências. Diário Oficial da União, Brasília, 26 de junho de 2014. Disponível em http://pne.mec.gov.br/18-planos-subnacionais-de-educacao/543-plano-nacional-de-educacaolei-n-13-005-2014. Acesso em 16 jul. 2020.

BRASIL. Base Nacional Comum Curricular. Brasília: MEC, 2017. Disponível em: http://basenacionalcomum.mec.gov.br/images/BNCC 20dez site.pdf. Acesso em 15 jul. 2020.

BRASIL. Ministério da Educação/Conselho Nacional de Educação. Parecer CNE/CP n. 5/2020, aprovado em 28 de abril de 2020. Reorganização do Calendário Escolar e da possibilidade de cômputo de atividades não presenciais para fins de cumprimento da carga horária mínima anual, em razão da Pandemia da COVID-19. Brasília: Ministério da Educação, 2020a.

BRASIL. Ministério da Educação/Conselho Nacional de Educação. Parecer CNE/CP n. 11/2020, de 13 de julho de 2020. Orientações Educacionais para a Realização de aulas e atividades pedagógicas presenciais e não presenciais no contexto da Pandemia. Brasília: Ministério da Educação, 2020b.

CÂMARA, Rosana Hoffman. Análise de conteúdo: da teoria à prática em pesquisas sociais aplicadas às organizações. Gerais - Revista Interinstitucional de Psicologia, São João del-Rei, v. 6, n. 2, jul./dez. 2013. p. 179-191.

CAMPOS, Claudinei José Gomes. Método de análise de conteúdo: ferramenta para a análise de dados qualitativos no campo da saúde. Revista Brasileira de Enfermagem, Brasília, v. 57, n. 5, set./out. 2004. p. 611-614.

CORREAA, Cintia Chung Marques. A BNCC: cultura, ideologia e poder. Revista Poder \& Cultura, Rio de Janeiro, v. 6, n. 11, jan./jun. 2019. p. 62-77.

GARCIA, Regina Leite; ESTEBAN, Maria Teresa; SERPA, Andréa. Saberes cotidianos em diálogo. Rio de Janeiro: De Petrus, 2015.

HOSTINS, Regina Celia Linhares; ROCHADEL, Olivia. Contribuições de Stephen Ball para o campo das políticas educacionais. Revista online de Politica e Gestão Educacional. Araraquara, v. 23, n. 1, jan./abr. 2019. p. 61-84.

LOPES, Alice Casimiro. Políticas curriculares: continuidade ou mudança de rumos? Revista Brasileira de Educação, Rio de Janeiro, n. 26, maio/jul./ago. 2004. p. 109-183.

MACEDO, Elizabeth. Currículo e conhecimento: aproximações entre educação e ensino. Cadernos de Pesquisa, v. 42, n. 147, set./dez. 2012. p. 716-737.

MOREIRA, Antonio Flavio Barbosa. Currículo, cultura e formação de professores. In: CONGRESSO ÍBERO-AMERICANO. Santa Maria, Rio Grande do Sul. 19 de abril de 2000. Educar, Curitiba, n. 17, 2001. p. 39-52.

MOREIRA, Antonio Flavio Barbosa; CANDAU, Vera Maria. Currículo, conhecimento e cultura. In: FERNANDES, Cláudia de Oliveira; FREITAS, Luiz Carlos de. Indagações sobre currículo: currículo e avaliação. Organização do documento: Jeanete Beauchamp, Sandra Denise Pagel, Ariciléia 
Ribeiro do Nascimento. Brasília: MEC, Secretaria de Educação Básica, 2007. Disponível em: http://portal.mec.gov.br/seb/arquivos/pdf/Ensfund/indag5.pdf. Acesso em 5 jul. 2020.

MOREIRA, Antonio Flavio Barbosa; SILVA, Tomaz Tadeu da. Currículo, cultura e sociedade. 10. ed. São Paulo: Cortez, 2008. 154 p.

MOREIRA, Antonio Flávio Barbosa Moreira. O atual processo de internacionalização do campo do currículo: estratégias e desafios. Educação, sociedade e culturas, Portugal, n. 37, 2012. p. 45-61.

OMS. Organização Mundial da Saúde. Folha Informativa COVID-19 (doença causada pelo novo coronavirus). Disponível em:

https://www.paho.org/bra/index.php?option $=$ com content\&view $=$ article\&id=6101:covid19\&I temid=875\# o-que-e. Acesso em 10 jul. 2020.

SAVIANI, Dermeval. Política educacional brasileira: limites e perspectivas. Revista de Educação, Campinas, n. 24, jun. 2008. p. 7-16.

YOUNG, Michael. Por que o conhecimento é importante para as escolas do século XXI? Tradução Tessa Bueno. Revisão técnica Cláudia Valentina Assumpção Galian. Cadernos de Pesquisa, São Paulo, v. 46, n. 159, jan./mar. 2016. p. 13-37.

\section{Informações dos autores:}

Flávia Marcele Cipriani

Universidade Católica de Petrópolis - UCP

E-mail: flaviamcipriani@yahoo.com.br

ORCID: https://orcid.org/0000-0001-7242-8418

Link Lattes: http://lattes.cnpq.br/7643895888544856

Antonio Flavio Barbosa Moreira

Universidade Católica de Petrópolis - UCP

E-mail: afmcju@gmail.com

ORCID: https://orcid.org /0000-0001-7097-0238

Link Lattes: http://lattes.cnpq.br/4949667751311748

Cintia Chung Marques Corrêa

Universidade Católica de Petrópolis - UCP

E-mail: cintia.chung@ucp.br

ORCID: 0000-0003-1429-9982

Link Lattes: http://lattes.cnpq.br/4691196404656135 